\title{
RETRACTED ARTICLE: Digital forensics system based on dynamic path prediction and the competitiveness of cross-border e-commerce SMEs
}

\author{
Chunqiong $\mathrm{Wu}^{1,2} \cdot$ Bingwen $\mathrm{Yan}^{1,2} \cdot$ Rongrui $\mathrm{Yu}^{1,2} \cdot$ Baoqin $\mathrm{Yu}^{1,2} \cdot$ Xiukao Zhou ${ }^{1,2} \cdot \mathrm{Yanliang} \mathrm{Yu}^{1,2} \cdot \mathrm{Na}^{\mathrm{C}} \mathrm{Chen}^{2,3}$
}

Received: 10 June 2021 / Accepted: 30 July 2021 / Published online: 11 August 2021

(C) The Author(s), under exclusive licence to Springer-Verlag London Ltd., part of Springer Nature 2021

The Editor-in-Chief and the Publisher have retracted this article because the content of this article is nonsensical. The peer review process was not carried out in accordance with the Publisher's peer review policy. Authors Chunqiong $\mathrm{Wu}$, Bingwen Yan, Rongrui $\mathrm{Yu}$, Baoqin $\mathrm{Yu}$ and $\mathrm{Na}$ Chen have not responded to correspondence regarding this retraction. The Publisher has not been able to obtain a current email address for authors Xiukao Zhou and Yanliang Yu. The online version of this article contains the full text of the retracted article as Supplementary Information.

Supplementary Information The online version contains supplementary material available at https://doi.org/10.1007/s00779-021-01615-3.

Chunqiong Wu

cqwu@ygu.edu.cn

1 Business College, Yango University, Fuzhou City 350015, Fujian Province, China

2 Big Data Business Intelligence Engineering Research Center of Fujian University, Fuzhou City 350015, Fujian Province, China

3 Software Engineering Institute, Lanzhou Institute Technology, Lanzhou City 730050, Gansu Province, China 